\title{
Reduction of Sodium Migration in Polymers by Addition of 15-Crown-5 Ether as Getter Substance
}

\author{
S. Schwab, ${ }^{\text {a,b,z }}$ J. P. H. Jung, ${ }^{\text {b J. Appenroth }},{ }^{a, b}$ E. Pittenauer, ${ }^{b}$ G. Allmaier, ${ }^{\text {b }}$ S. Gruber, ${ }^{b, c}$ \\ M. Bauer, ${ }^{\mathrm{d}}$ S. Miethaner, ${ }^{\mathrm{d}}$ M. Nelhiebel, ${ }^{\mathrm{a}}$ and H. Hutter ${ }^{\mathrm{b}}$ \\ ${ }^{a}$ KAI Kompetenzzentrum Automobil- u. Industrieelektronik GmbH, 9524 Villach-St.Magdalen, Austria \\ ${ }^{b}$ Vienna University of Technology (TU Wien), Institute for Chemical Technologies and Analytics, 1060 Wien, Austria \\ ${ }^{c}$ Infineon Technologies Austria AG, 9500 Villach, Austria \\ ${ }^{d}$ Infineon Technologies Germany AG, 93049 Regensburg, Germany
}

\begin{abstract}
Already small amounts of ion contamination within sensitive areas of high voltage transistors can cause severe damage to semiconductor devices. Therefore, it is of utmost importance to hinder mobile ions from reaching critical regions (e.g., the gate oxide layer). To protect semiconductor devices from environmental influences and contamination, polymers are used for chip encapsulation. Reduction of ion migration within these polymers can increase the reliability of the semiconductor device. Crown ethers are well known to form stable complexes with alkali cations. Within this work the influence of 15 -crown-5 ether on the sodium migration in poly-methyl methacrylate and polyimide will be evaluated by means of ion conductivity measurements.

(C) The Author(s) 2017. Published by ECS. This is an open access article distributed under the terms of the Creative Commons Attribution Non-Commercial No Derivatives 4.0 License (CC BY-NC-ND, http://creativecommons.org/licenses/by-nc-nd/4.0/), which permits non-commercial reuse, distribution, and reproduction in any medium, provided the original work is not changed in any way and is properly cited. For permission for commercial reuse, please email: oa@electrochem.org. [DOI: 10.1149/2.0111707jss] All rights reserved.

(cc) BY-NC-ND
\end{abstract}

Manuscript submitted February 6, 2017; revised manuscript received March 29, 2017. Published May 11, 2017.

Reliability problems caused by mobile ions are well known issues in the semiconductor industry. ${ }^{1}$ The issue of ion induced damage has been minimized for most semiconductor devices by the use of various counter strategies, such as barrier layers (e.g., silicon nitride $\left(\mathrm{Si}_{3} \mathrm{~N}_{4}\right)^{2}$ ), getter layers (e.g., borophosphosilicate glass (BPSG) ${ }^{3}$ ) or by the elimination of possible contamination sources. ${ }^{4}$ Nevertheless the problem does still exist for high power devices such as transistors. ${ }^{5}$ High operation voltages result in strong electric fields within these devices, which can induce ion migration to sensitive areas, such as the gate oxide. Already small amounts of ions (approx. $10^{10}$ ions $/ \mathrm{cm}^{2}$ ${ }^{6,7}$ ) within these areas can cause a drift in the threshold or breakdown voltage of the transistor, thus resulting in malfunction of the devices.

A possible approach to tackle this problem is the elimination of ion contamination sources, which was effectively done for the materials used in the transistor chip itself. ${ }^{8}$ However, this is not the case for encapsulation materials, such as polymers and mold compounds. These materials are used to protect the chip against environmental influences, for example physical stress, humidity or corrosion. Based on the production and deposition process of these compounds, mobile ion contamination cannot be avoided. ${ }^{9}$ Sodium is one of the main risks regarding ion migration, due to the high natural abundance and small ionic radius. Therefore, it is of utmost importance to develop strategies to hinder sodium ions from reaching sensitive areas of the device.

Crown ethers are well known to form stable complexes with sodium ions. ${ }^{10}$ If crown ethers are added to the polymer layers such as poly(methyl methacrylate) (PMMA) and polyimide (PI), sodium migration should be decreased as the formed complexes are way larger than free sodium ions. It is therefore important to evaluate, if sodiumcrown-ether complexes can be formed within the polymers. In order to do so, laser desorption ionization mass spectrometry (LDI-MS) measurements were carried out. Due to the fact that LDI is a soft desorption/ionization technique ${ }^{11}$ it is possible to desorb inorganic sodium 15-crown-5 ether complexes ([M(crown ether) $\mathrm{Na}]^{+}$, at $\mathrm{m} / \mathrm{z}$ 243), i.e. intact host-guest complexes, without significant fragmentation during the soft desorption process, thus proving evidence for the existence of complexed sodium within the layer.

Furthermore, we want to compare field induced sodium migration in the polymeric layers with and without crown ether by bias temperature stress tests similar to the one described in Ref. 12. The experimental setup is described in the following section. Polymer layers (doped with crown ether vs non-doped) were deposited on a back

${ }^{\mathrm{z} E}$-mail: stefan.schwab@k-ai.at side metallized $\mathrm{Si} / \mathrm{SiO}_{2}$ wafer. On top of the polymer, a gold electrode was sputter-deposited. The two electrodes have been contacted to apply a positive charge on the gold electrode to induce an electrical field in the sample. Mobile ions can now migrate from the polymeric layers into the $\mathrm{SiO}_{2}$ layer toward the $\mathrm{Si} / \mathrm{SiO}_{2}$ interface. This ionic current can be measured by a $1 \mathrm{M} \Omega$ shunt resistor. Due to the insulating $\mathrm{SiO}_{2}$ layer, there is no electron conductivity between the electrodes (resistivity $\sim 10^{16} \Omega^{13}$ possible tunneling current is below the detection limit). The migrated ionic charge can be calculated following Equation $1(\mathrm{Q}(\mathrm{t})$. . . migrated charge, $\mathrm{I}(\mathrm{t})$. . . measured current, $\mathrm{t}$. . time).

$$
Q(t)=\int I(t) * d t
$$

Assuming that sodium is the main migrating species during the experiment, the number of migrated sodium ions can be calculated using Equation $2\left(n_{\mathrm{Na}^{+}}(t) \ldots\right.$ number of migrated sodium ions, $q_{0} .$. elemental charge).

$$
n_{N a^{+}}(t)=\frac{Q(t)}{q_{0}}
$$

The calculated number of migrated sodium ions at the end of the experiment $\left(n_{\mathrm{Na}^{+}}(\right.$end $\left.)\right)$can be compared to the amount of sodium atoms added to the polymer layers (see Equation $3 ; c_{N a^{+}} \ldots$ sodium concentration in the polymeric layer, $d \ldots$ thickness of the layer, $A \ldots$ surface of the layer).

$$
n_{N a^{+}}=c_{N a^{+}} * d * A
$$

If sodium migration can be reduced by the addition of crown ethers, the measured charge should be decreased accordingly.

\section{Experimental}

Sample preparation.-Polymer solutions for spin coating with known sodium concentration were prepared by dissolving PMMA (Sigma Aldrich, $\mathrm{M}_{\mathrm{w}} 996000$ (GPC)) and PI (H P Polymers, P84polyimide SGG) in acetonitrile (ABCR, purity $99.9 \%$ (for HPLC)). Sodium trifluoromethanesulfonate (Sigma Aldrich, purity 98\%) was added to provide a constant sodium concentration. Different amounts of 1,4.7,10,13-pentaoxacyclopentadecane (15-crown-5, Sigma Aldrich, purity 98\%), reaching from 0 (reference, i.e. pure polymer dissolved in acetonitrile) up to $\mathrm{Na}^{+}: 15$-crown-5 molar ratio of $1: 20$ were added to the solutions. 15 -crown-5 was used as obtained by the provider. A detailed list of the used polymer solutions is summarized in Table I. 
Table I. Summary of the measured samples.

\begin{tabular}{|c|c|c|c|c|c|c|c|}
\hline $\begin{array}{c}\text { Sample number } \\
\#\end{array}$ & $\begin{array}{c}\text { Polymer } \\
\#\end{array}$ & $\begin{array}{l}\text { Solvent } \\
\quad \#\end{array}$ & $\begin{array}{c}\text { Concentration of the } \\
\text { polymer in the solvent } \\
\text { [wt } \%]\end{array}$ & $\begin{array}{l}\text { Spinning speed } \\
{[\mathrm{RPM}]}\end{array}$ & $\begin{array}{c}\text { Layer thickness (measured } \\
\text { with interferometer) } \\
{[\mathrm{nm}]}\end{array}$ & $\begin{array}{c}\mathrm{Na}^{+} \text {concentration } \\
\text { in the final layer } \\
{\left[\text { ions } / \mathrm{cm}^{3}\right]}\end{array}$ & $\begin{array}{c}\text { 15-crown- } 5 \text { concentration } \\
\text { in the final layer } \\
{\left[\text { ions } / \mathrm{cm}^{3}\right]}\end{array}$ \\
\hline 1 & PMMA & acetonitrile & 1,5 & 3000 & 50 & 0 & 0 \\
\hline 3 & PMMA & acetonitrile & 1,5 & 3000 & 50 & $1.0 \mathrm{E}+19$ & $1.0 \mathrm{E}+19$ \\
\hline 4 & PMMA & acetonitrile & 1,5 & 3000 & 50 & $1.0 \mathrm{E}+19$ & $5.0 \mathrm{E}+19$ \\
\hline 5 & PI & acetonitrile & 8 & 3700 & $300^{*}$ & $2.5 \mathrm{E}+19$ & $1.0 \mathrm{E}+20$ \\
\hline
\end{tabular}

*Preparation of PI films with the same layer thickness as the PMMA samples was not possible due to limitations with the spinning speed/solvent concentration.

To ensure high quality of the $\mathrm{SiO}_{2}$ layers, the wafer substrate was cleaned prior to oxidation by a HF dip ( $5 \mathrm{~min}$ ) and a Radio Corporation of America (RCA) cleaning step. ${ }^{14}$ The oxide was produced at $1000^{\circ} \mathrm{C}$ with an $\mathrm{O}_{2} / \mathrm{HCl}$ atmosphere (dry oxide). The oxide at the back side of the wafer was etched and a metallization layer was deposited. The wafer was diced in $10 \times 10 \mathrm{~mm}$ pieces.

Before testing, prepared polymer solutions were deposited by spin coating on top of the silicon dioxide layer. After drying at $80^{\circ} \mathrm{C}$ (10 $\mathrm{min})$, a $100 \mathrm{~nm}$ gold layer was deposited on top of the polymer layer by sputter coating. A sputter mask of $8 \times 8 \mathrm{~mm}$ was used to ensure that no unwanted electrical contact with the wafer substrate can occur at the edges of the sample. A scheme of the sample structure is depicted in Figure 1.

Laser desorption ionization mass spectrometry (LDI-MS) measurements.-Positive ion LDI-MS measurements were carried out using an Axima $\mathrm{TOF}^{2}$ tandem time of flight mass spectrometer (Shimadzu Kratos Analytical) consisting of a linear TOF/curved field reflectron TOF (design described elsewhere) ${ }^{15}$ equipped with a $20 \mathrm{~Hz}$ $\mathrm{N}_{2}$ laser $(\lambda=337 \mathrm{~nm})$. Full mass spectra were acquired in the reflectron mode by rastering an area of $1 \times 1 \mathrm{~mm}$ containing 500 single laser pulses. For tandem TOF experiments, i.e. high energy CID (collision induced dissociation), the ion gate for precursor ion selection was set to $\pm 3 \mathrm{Da}$ and the collision gas pressure (collision gas: $\mathrm{He}$ ) to $5 \times 10^{-5}$ mbar. A slightly elevated laser irradiance (roughly $+10 \%$ ) was applied and 2500 single unselected laser pulses were used for acquiring the CID spectra.

Bias temperature $(B / T)$ stress measurements.-In order to measure the influence of 15 -crown-5 on the sodium migration in polymers, a measurement setup similar to the one described in Ref. 12 was used. A power supply (FuG Elektronik) was used to apply a positive voltage of $21 \mathrm{~V}$ to the sputtered gold electrode. Ionic current was measured using a $1 \mathrm{M} \Omega$ shunt resistor and a 6.5 digit digital multi-meter (Keith-

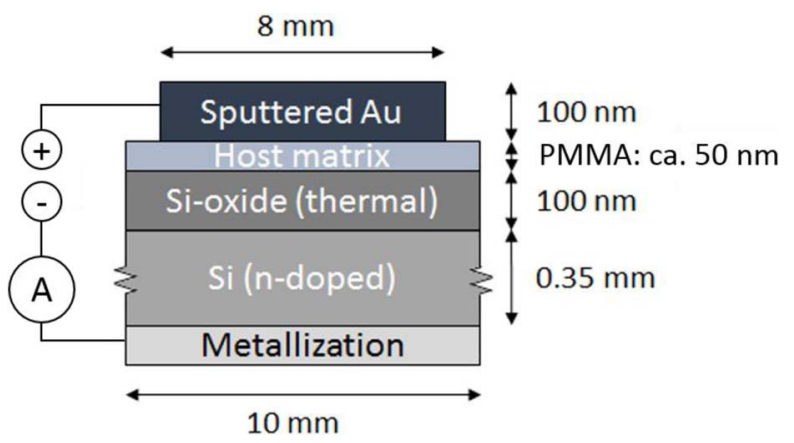

Figure 1. Scheme of the measurement setup and sample geometry. The host matrix was deposited on the $\mathrm{SiO}_{2}$ layer by spin coating. The sputtered gold electrode is slightly smaller than the layers below to reduce the risk of unwanted currents at the edges of the sample. ley Instuments). An oven platform (Linkam Scientific Instruments) which was controlled by an oven controller (Eurotherm) was used to heat the samples.

Time-of-flight secondary ion mass spectrometry (TOF-SIMS) measurements.-TOF-SIMS depth profiles of the samples prior to and after bias temperature stress were acquired using a TOF-SIMS 5 instrument (IonTOF). A $25 \mathrm{keV} \mathrm{Bi}^{+}$primary ion beam was used for analysis (high current bunched mode) and a $2 \mathrm{keV} \mathrm{O}_{2}{ }^{+}$beam was used for sputtering. The analysis area was set to $50 \times 50 \mu \mathrm{m}$ and the sputter crater size was set to $300 \times 300 \mu \mathrm{m}$. Low energy electron flooding $(21 \mathrm{eV})$ was used to reduce charging effects during the measurement.

\section{Results and Discussion}

Measurement of sodium-15-crown-5 complexes within the polymeric layers. - In order to prove the formation of the host-guest complex, i.e. sodium-15-crown-5 complex, LDI-MS measurements were carried out on a spin coated sample. The resulting mass spectrum of sample $4\left(\mathrm{Na}^{+}:\right.$15-crown-5 molar ratio $\left.=1: 5\right)$ is shown in Figure $2 \mathrm{a}$. A reasonable abundant sodium-15-crown- 5 complex was detected but no protonated form of 15 -crown-5 was observed. The external calibrated mass spectrum exhibited a $\mathrm{m} / \mathrm{z}$ value of 243.11 and showed a $\Delta \mathrm{m}$ of -0.01 Da compared to the theoretical monoisotopic value $(\mathrm{m} / \mathrm{z} 243.12)$. To verify the host-guest complex on a structural level a high energy $(20 \mathrm{keV}) \mathrm{CID}$ experiment was performed selecting the $\mathrm{m} / \mathrm{z} 243$ as precursor ion. The generated fragment ion spectrum (CID spectrum) of sample 4 is shown in Figure $2 \mathrm{~b}$. A very abundant sodium ion peak at $\mathrm{m} / \mathrm{z} 23$ in the CID spectrum proves that the precursor ion at $\mathrm{m} / \mathrm{z}$ ratio of 243 is the host-guestcomplex independent of the molecular mass value. This result confirms the formation of a stable sodium-15-crown-5 complex within the polymer layer.

Results of the migration measurements in PMMA.-The PMMA samples with different crown ether amounts were measured with a bias of $21 \mathrm{~V}$ at $150^{\circ} \mathrm{C}$ and $180^{\circ} \mathrm{C}$. At least three measurements were carried out for each sample type. The migrated charge was calculated using Equation 1. The mean charge values as well as the standard deviation at $150^{\circ} \mathrm{C}$ are depicted in Figure $3 \mathrm{a}$. The results of PMMA with a sodium concentration of $1 \times 10^{19}$ ions $/ \mathrm{cm}^{3}$ with different crown ether concentrations are compared with the one without sodium (pure PMMA). The measured charge of the pure (non-contaminated) sample indicates that there is some intrinsic contamination originating either from the PMMA or the used solvents. It can be seen that the addition of crown ether slows down the migration of sodium. The higher the concentration of crown ether, the slower the charge transfer. It is further evident that at the end of the experiment, the final charge value for the samples with crown ether is lower than the one without. This indicates that a part of the sodium was permanently complexed by the crown ether molecules and therefore no longer able to migrate during the experiment. The charge over time plots for the crown ether containing samples were normalized to the charge without crown 


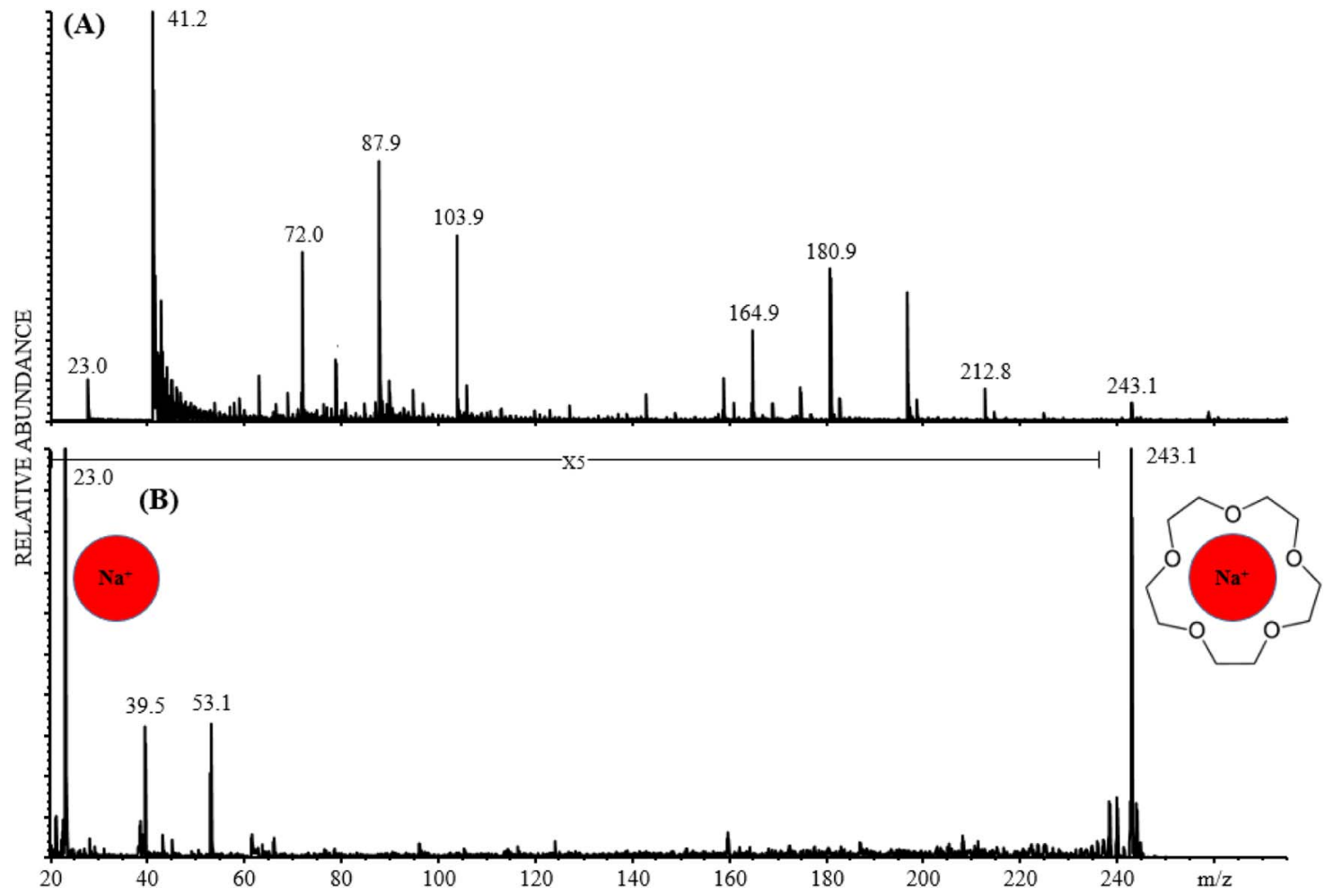

Figure 2. Positive ion LDI-RTOF mass spectrum (A) and high-energy CID TOF/RTOF spectrum (B) of sample 4. A peak at m/z 243.1 in the mass spectrum (A) indicates that a sodium-15-crown-5 complex is formed and stable within the polymer matrix. Panel (B) shows the CID spectrum exhibiting the fragmentation of the sodium-carrying precursor ion $(\mathrm{m} / \mathrm{z} 243.1)$ at a collision energy of $20 \mathrm{keV}$. The very abundant signal at $\mathrm{m} / \mathrm{z} 23.0$ indicates that the selected precursor ion is indeed the sodium-15-crown-5 complex.

ether for better comparison (using Equation 4) and are depicted in Figure $3 b$.

$$
Q_{\text {Normalized }}(t)=\frac{Q_{\text {Crown }}(t)}{Q_{\text {without crown }}(t)}
$$

At the beginning of the experiment the normalized charge is low which indicates that sodium migration is slowed down for the samples with crown ethers. The final charge value reached at the end of the experiment, is decreased by increasing the crown ether concentration indicating that the higher the crown ether concentration the higher the reduction of sodium migration within the PMMA layer.

Results of the sodium migration measurements at $180^{\circ} \mathrm{C}$ are depicted in Figure 4a. The data shows that the addition of 15-crown-5 to the PMMA layer leads to a decreased sodium migration. Nevertheless, the effect is minor compared to the results at $150^{\circ} \mathrm{C}$, which can be explained by the fact that de-complexation might occur at higher temperatures. This is in good agreement with the literature since complexation studies of sodium with crown ethers in various solvents
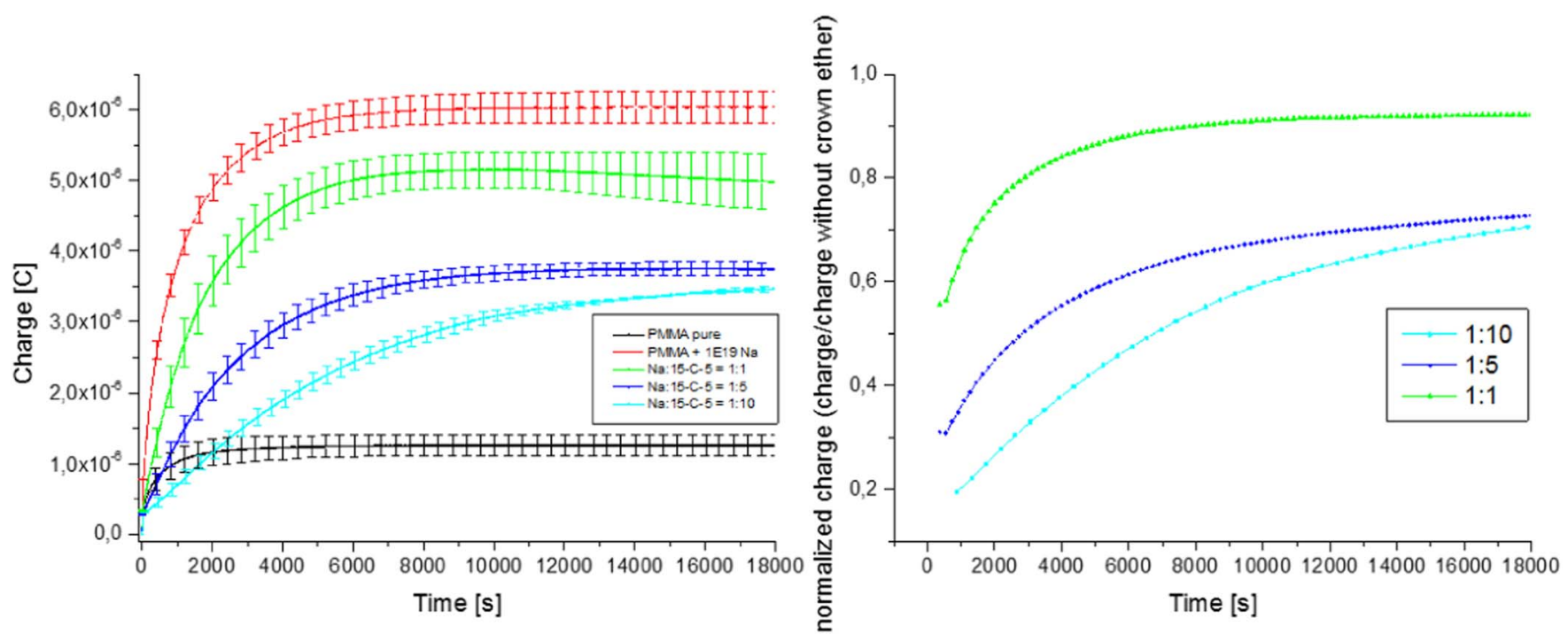

Figure 3. Results of the current measurements of sodium in PMMA with different Na: 15 -crown-5 molar crown ether ratios at $150^{\circ} \mathrm{C}$ (a) and normalized charge plots for the samples with crown ether (b) which are calculated with Equation 2. 
(a)

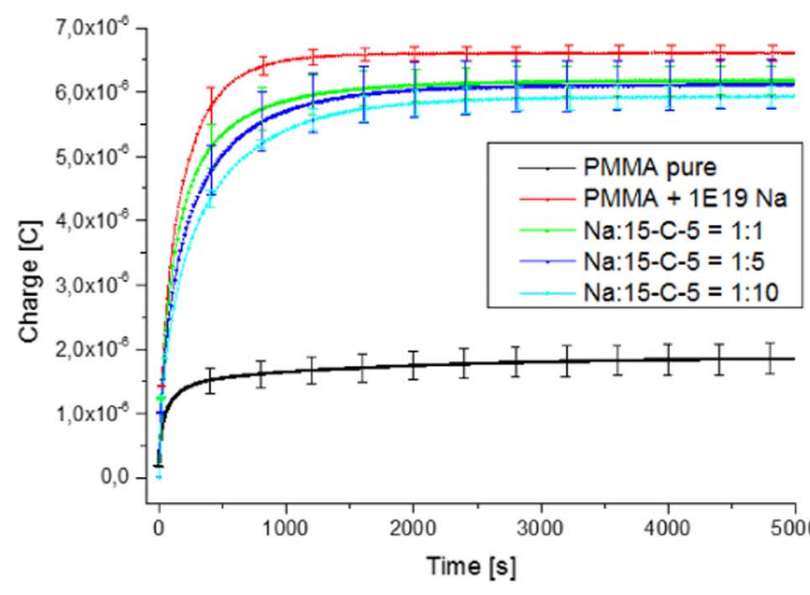

(b)

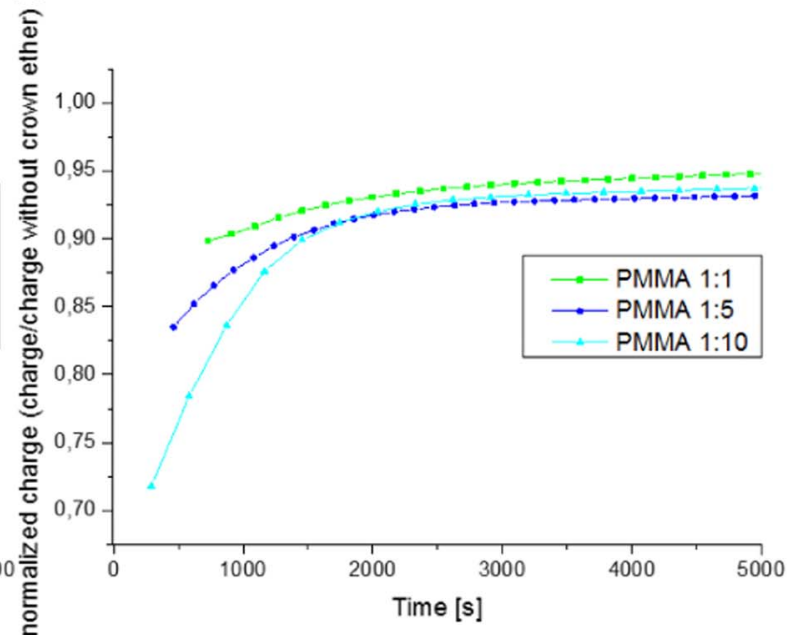

Figure 4. Results of the current measurements of sodium in PMMA with different molar crown ether ratios at $180^{\circ} \mathrm{C}$ (a) and normalized (to the charge without crown ether) charge plots for the samples with crown ether (b) which are calculated with Equation 2.

(e.g. acetonitrile) showed that complex formation is exothermic $(\Delta \mathrm{H}$ $<0) .{ }^{16}$ Figure $4 \mathrm{~b}$ shows the normalized charge values at $180^{\circ} \mathrm{C}$. It shows that there is less sodium migration for the samples with crown ether at the beginning of the experiment. After approximately 2000 $\mathrm{s}$, the normalized migrated charge reaches a value of over $90 \%$. This indicates that sodium migration is reduced with the addition of 15crown-5 at $180^{\circ} \mathrm{C}$, but in the end of the experiment, nearly all the sodium has moved from the PMMA layer into the $\mathrm{SiO}_{2}$ layer.

The final charge values as well as the time constants (time until $63 \%$ of the final charge is reached: $\left.\mathrm{C}_{(\mathrm{t})}=\mathrm{C}_{\max } *\left(1-\mathrm{e}^{-1}\right)\right)$ are shown in Table II. The normalized charge values as well as the normalized time constants are shown in Figure 5. At $150^{\circ} \mathrm{C}$ the final charging value seems to be exponentially decreased with the crown ether portion. At $180^{\circ} \mathrm{C}$ however, only a small decrease of the maximum charge was achieved by the addition of 15 -crown- 5 . The final charge value was hardly decreased by increasing the crown ether ratio. The time constants measured at both temperatures showed a linear increase with the crown ether ratio. However, the increase of the time constants with the crown ether ratio was much more pronounced at $150^{\circ} \mathrm{C}$ compared to the one at $180^{\circ} \mathrm{C}$.

Charge calculation and comparison.-Figure 3a and Figure 4 show that the final charge value of the samples without crown ether is approximately $6 \times 10^{-6} \mathrm{C}$. Equation 2 was used to calculate the number of sodium ions corresponding to the final charge. The value was compared to the one calculated by the $\mathrm{Na}^{+}$concentration in the polymer layer using Equation 3. The results of the calculation are shown in Table III. As the two calculated values are in good agreement, it is evident that the whole sodium amount within the sample migrates during the bias temperature experiments of the PMMA layers without crown ether additive.
Analysis of the stressed samples after the experiment.-TOFSIMS depth profiles were carried out to investigate where the sodium ions migrate to during the experiment. The results of the TOF-SIMS measurement prior to and after bias/temperature stress are depicted in Figure 6. As described in Ref. 17, the surface of non-conductive samples is positively charged during sputtering in TOF-SIMS depth profiling. Due to this known effect, sodium cannot be detected in the insulating layers since it drifts toward the interfaces during the measurements. The small sodium peak at the $\mathrm{SiO}_{2} / \mathrm{Si}$ interface is caused by the same effect. However, the increased $\mathrm{Na}^{+}$signal after the experiment at the $\mathrm{Si} / \mathrm{SiO}_{2}$ interface compared to the one prior to the measurement shows that sodium migrated from the PMMA layer to the interface during the bias temperature stress experiment. Due to the fact that TOF- SIMS measurements suffer from severe matrix effects, ${ }^{18}$ quantitative estimation of the migrated ions by means of the TOF-SIMS results could not be acquired.

Results of the migration measurements in PI.-Measurement of sodium migration in PI at $150^{\circ} \mathrm{C}$ could not be done with the setup described as the ion current at $150^{\circ} \mathrm{C}$ was too low (even in the samples without crown ether). Therefore, the experiments were only carried out at $180^{\circ} \mathrm{C}$. The results of the measurement of the sodium migration with and without crown ether at $180^{\circ} \mathrm{C}$ are depicted in Figure 7a. The final charge value of the samples with crown ether is higher than the one measured with the PMMA sample. This is due to the fact that the layer thickness of the PI layers is higher than the one of the PMMA layers. Furthermore, a higher sodium concentration was used for the measurements with PI (as shown in Table I). It can be seen that the addition of 15-crown-5 leads to a strongly reduced sodium migration in PI. The effect is way higher than the one measured for the PMMA layers. Figure $7 b$ shows the normalized charge

Table II. Final charge values and time constants of the PMMA measurements.

Crown ether ratio

\begin{tabular}{c}
{$[\mathrm{Na}+:$ crown ether] } \\
\hline $1: 0$ \\
$1: 1$ \\
$1: 5$ \\
$1: 10$
\end{tabular}

$150^{\circ} \mathrm{C}$ measurements
$6,03 \mathrm{E}-06$
$5,10 \mathrm{E}-06$
$3,75 \mathrm{E}-06$
$3,57 \mathrm{E}-06$

$[\mathrm{C}$

Final charge values

$180^{\circ} \mathrm{C}$ measurements
$6,61 \mathrm{E}-06$
$6,18 \mathrm{E}-06$
$6,12 \mathrm{E}-06$
$5,93 \mathrm{E}-06$

[s]

\section{Time constant (time until \\ $63 \%$ of max. charge is reached)}

\begin{tabular}{cc}
\hline $150^{\circ} \mathrm{C}$ measurements & $180^{\circ} \mathrm{C}$ measurements \\
\hline 995 & 141 \\
1621 & 171 \\
2523 & 207 \\
5232 & 274
\end{tabular}



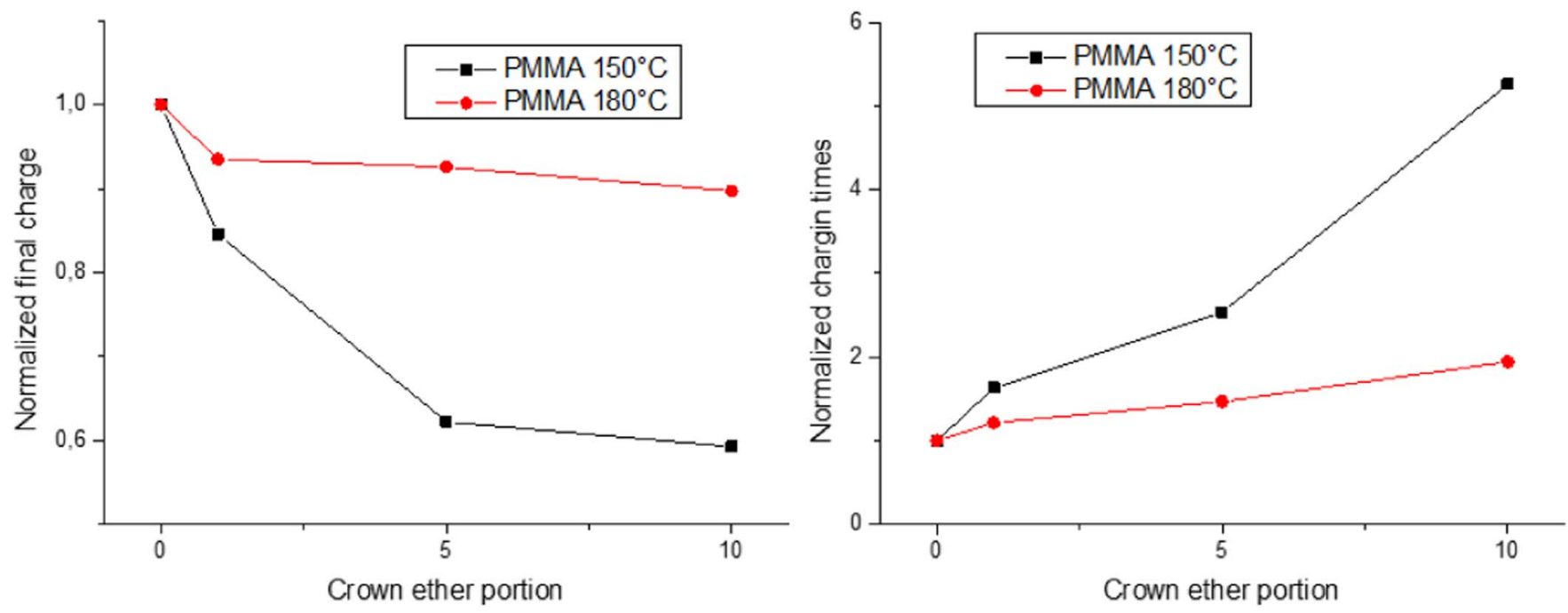

Figure 5. Relative maximum charge and relative charging times in PMMA.

Table III. Results of the calculation of sodium atoms within the PMMA layers.

\begin{tabular}{ccc} 
& $\begin{array}{c}\text { Calculated } \\
\text { sodium atoms }\end{array}$ & $\begin{array}{c}\text { Calculated } \\
\text { error }\end{array}$ \\
\hline $\begin{array}{c}\text { Calculated with the final charge value } \\
\text { Calculated with the host matrix concentration }\end{array}$ & $2.99 \mathrm{E}+13$ & $3.20 \mathrm{E}+12$ \\
& & $4.50 \mathrm{E}+12$
\end{tabular}

plot. It shows a completely different behavior than the results with the PMMA samples. During the first seconds of the experiment, the normalized charge value is close to 1 . We believe that this is the case due to the fact that non-complexed sodium in the PI layer will migrate at the beginning of the experiment. After this initial migration most of the sodium in the layer is complexed by 15 -crown-5 and therefore cannot migrate any more. In the sample without crown ether, sodium will migrate during the whole experiment which leads to a decreasing normalized charge over time. At the end of the experiment, only about $10 \%$ of the sodium atoms within the PI layer with the 15-crown-5 additive were able to migrate. This shows that sodium migration in PI can be strongly reduced by the addition of 15 -crown-5.
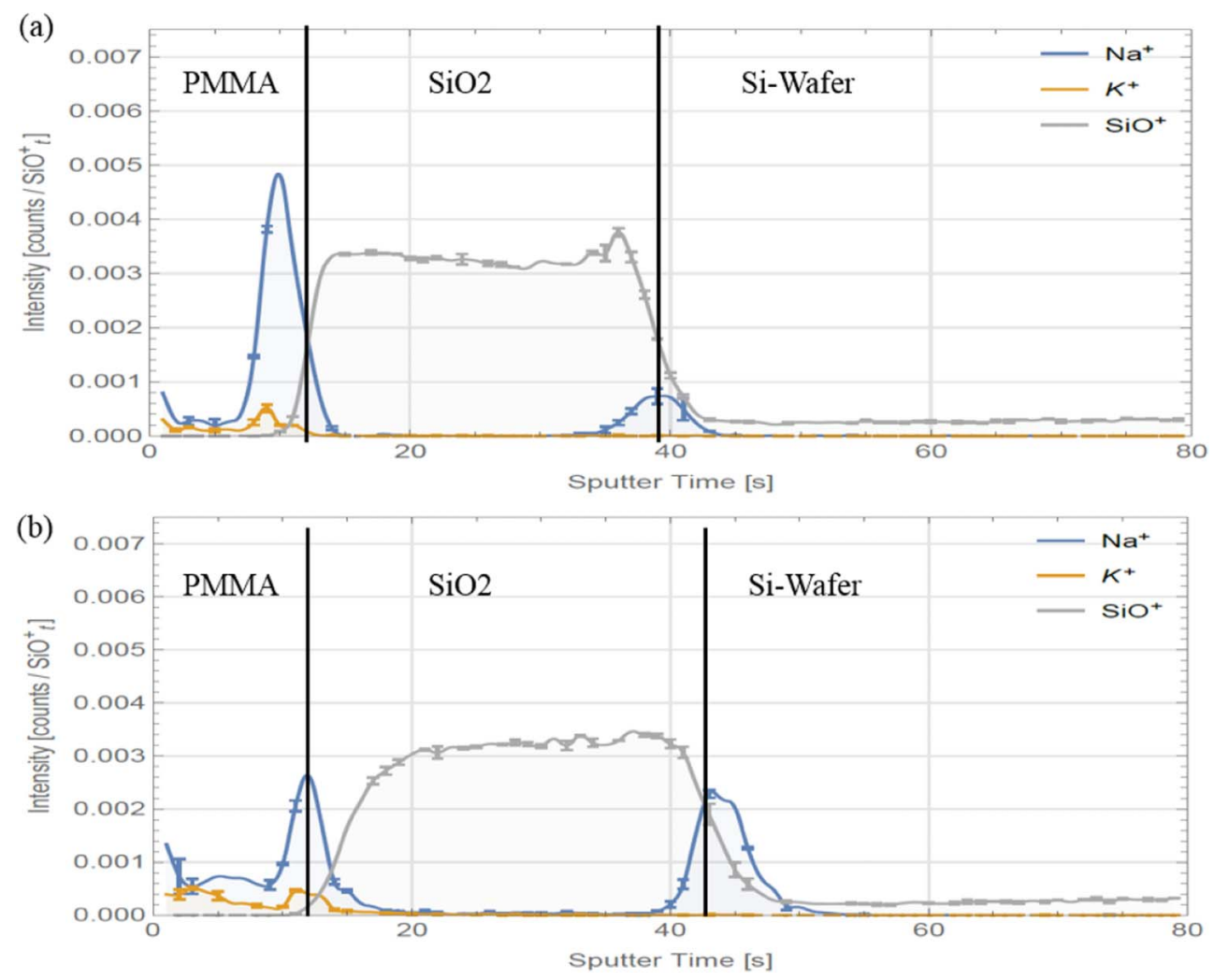

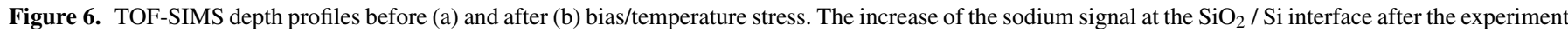
shows that sodium migrates through the PMMA and the $\mathrm{SiO}_{2}$ layer to the $\mathrm{Si} / \mathrm{SiO}_{2}$ interface during the experiment. 

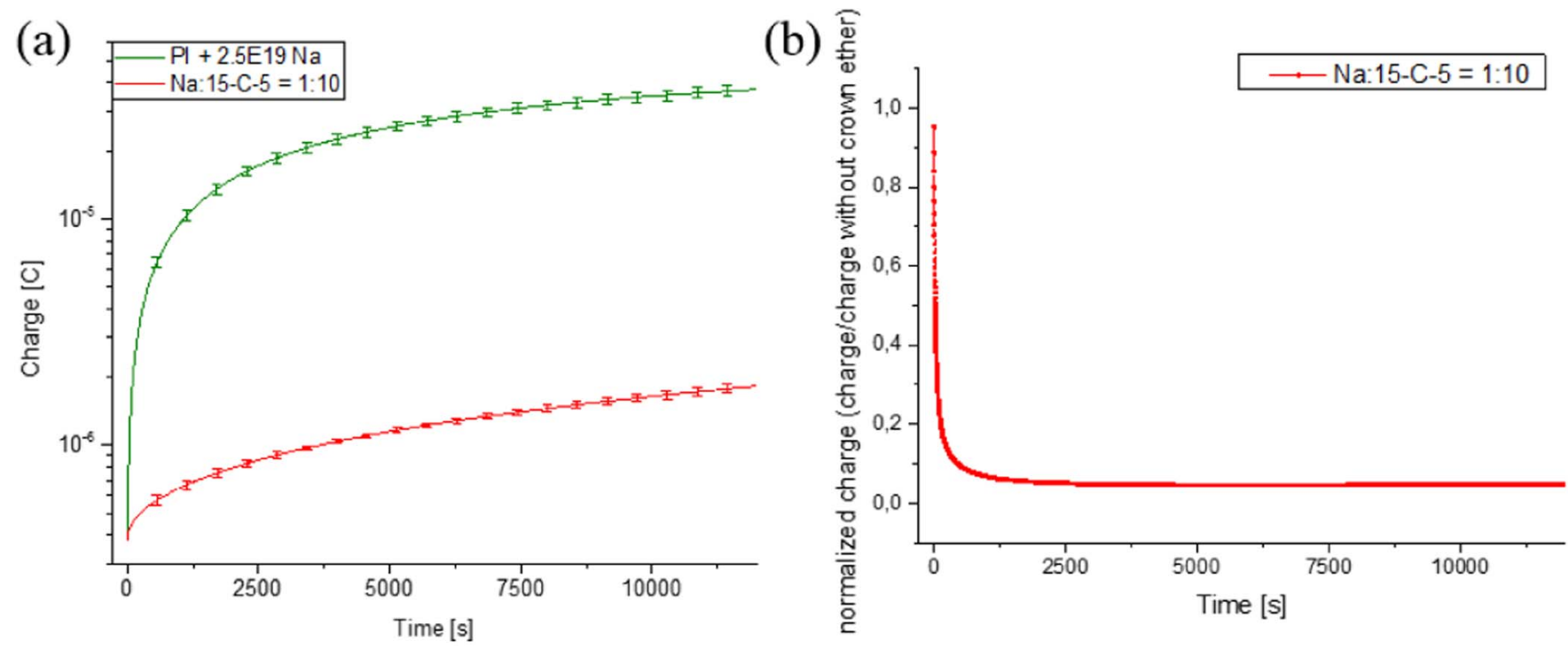

Figure 7. Results from the sodium migration in PI without crown ether (upper curve) and with a $\mathrm{Na}^{+}$to 15 -crown-5 ration of 1:10 (bottom line) (a) and normalized charge (b) at $180^{\circ} \mathrm{C}$. The sodium migration is strongly reduced by the addition of the crown ether (mind the logarithmic scale).

TOF-SIMS measurements after the bias temperature experiments were not possible since the charging effects during the measurements prohibited sputtering of the PI layer with our setup.

\section{Conclusions and Outlook}

Within this work it was shown that sodium forms host-guest complexes with 15-crown-5 that are stable within the PMMA and PI matrix by LDI-MS and CID measurements. It was further shown that the addition of crown ether to the polymers can reduce ion migration and the higher the crown ether concentration, the larger the effect of reduction in ion migration. For PMMA, the getter effect is smaller at $180^{\circ} \mathrm{C}$ than at $150^{\circ} \mathrm{C}$.

It was shown that the getter effect is dependent on the polymer species as it was stronger with PI than with PMMA. The difference of the getter effect can be explained by the fact that PMMA belongs to the class of chain-flexible polymers, whereas PIs are rigid-rod polymers in the vast majority of cases. It was proven by charge comparison that the measured electrical current is equal to the sodium current within the sample. Sodium ions migrated from the polymer layer to the $\mathrm{Si} / \mathrm{SiO}_{2}$ interface, which was proven by comparing TOF-SIMS results of sample prior to current measurements to the results after current measurements.

In the future, measurements with PI at higher temperatures are planned to evaluate the temperature dependence of the gettering effect. Furthermore, TOF-SIMS depth profiling after the bias-temperature stress tests by sputtering with large argon clusters ${ }^{19}$ is planned in the future as depth profiling with $\mathrm{O}_{2}{ }^{+}$was not possible due to charging effects. Furthermore, differential scanning calorimetry measurements are planned to ensure that there is no phase segregation of the crown ether in the polymer matrix. ${ }^{20}$ As the addition of crown ether to a PI layer is limited (too much of additives will strongly change the physical behavior of the polymer), new PIs will be synthesized with crown ethers within the polymer backbone. This might allow the usage of higher concentration of the crown ether functionalities within the polymer, thus leading to an increased gettering effect.

\section{Acknowledgments}

Special thanks are due Wolfgang Tomischko, Kurt Piplits and
Johannes Frank (Vienna University of Technology) for their help in developing and building the measurement setup for the temperature bias stress experiments. This work was jointly funded by the Austrian Research Promotion Agency (FFG, Project No. 854247) and the Carinthian Economic Promotion Fund (KWF, contract KWF$1521 / 28101 / 40388)$.

\section{References}

1. Y. Nishi and R. Doering, Handbook of Semiconductor Manufacturing Technology, Second Edition, CRC Press (2007).

2. J. V. Dalton and J. Drobek, Journal of The Electrochemical Society, 115, 865 (1968).

3. B. El-Kareh, Fundamentals of Semiconductor Processing Technology, Springer US (2012).

4. R. Kohli and K. L. Mittal, Developments in Surface Contamination and Cleaning, Vol. 1: Fundamentals and Applied Aspects, Elsevier Science (2015).

5. H. Bentarzi, Transport in Metal-Oxide-Semiconductor Structures: Mobile Ions Effects on the Oxide Properties, Springer Berlin Heidelberg (2011).

6. E. H. Snow, A. S. Grove, B. E. Deal, and C. T. Sah, Journal of Applied Physics, 36 1664 (1965).

7. K. S. Dieter, in Defects in Microelectronic Materials and Devices, CRC Press (2008).

8. K. A. Reinhardt and W. Kern, Handbook of Silicon Wafer Cleaning Technology, (2nd Edition), in, William Andrew Publishing.

9. M. Pecht, E. M. Bumiller, D. A. Douthit, and J. Pecht, Contamination of Electronic Assemblies, CRC Press, Boca Raton, Florida (2002).

10. C. J. Pedersen, Journal of the American Chemical Society, 89, 7017 (1967).

11. M. Karas and R. Krüger, Chemical Reviews, 103, 427 (2003).

12. S. Krivec, M. Buchmayr, T. Detzel, M. Nelhiebel, and H. Hutter, Surface and Interface Analysis, 42, 886 (2010).

13. CRC Materials Science and Engineering Handbook, Third Edition, CRC Press, Boca Raton (2000).

14. W. Kern, Journal of The Electrochemical Society, 137, 1887 (1990).

15. O. Belgacem, A. Bowdler, I. Brookhouse, F. L. Brancia, and E. Raptakis, Rapid Communications in Mass Spectrometry, 20, 1653 (2006).

16. M. Jóźwiak, Journal of Solution Chemistry, 31, 589 (2002).

17. S. Krivec, T. Detzel, M. Buchmayr, and H. Hutter, Applied Surface Science, 257, 25 (2010).

18. J. C. Vickerman and D. Briggs, TOF-SIMS: Materials Analysis by Mass Spectrometry, in, SurfaceSpectra/IM Publications (2013).

19. A. G. Shard, R. Havelund, M. P. Seah, S. J. Spencer, I. S. Gilmore, N. Winograd, D. Mao, T. Miyayama, E. Niehuis, D. Rading, and R. Moellers, Analytical Chemistry, 84, 7865 (2012).

20. P. van de Witte, A. Boorsma, H. Esselbrugge, P. J. Dijkstra, J. W. A. van den Berg, and J. Feijen, Macromolecules, 29, 212 (1996). 